\title{
Influência do tempo de incubação e do tamanho de partículas sobre os teores de compostos indigestíveis em alimentos e fezes bovinas obtidos por procedimentos in situ
}

\author{
André Oliveira Casali ${ }^{1}$, Edenio Detmann ${ }^{2}$, Sebastião de Campos Valadares Filho일 ${ }^{2}$ José Carlos \\ Pereira $^{2}$, Lara Toledo Henriques ${ }^{3}$, Samuel Galvão de Freitas ${ }^{4}$, Mário Fonseca Paulino ${ }^{2}$
}

\author{
1 Programa de Pós-graduação, Universidade Federal de Viçosa, Viçosa-MG, CEP: 36571-000. \\ 2 Departamento de Zootecnia, Viçosa-MG. Pesquisador do CNPq. \\ ${ }^{3}$ Bolsista PRODOC - CAPES, DZO-UFV, Viçosa-MG, CEP: 36571-000. \\ ${ }^{4}$ Curso de graduação em Zootecnia, DZO-UFV. Bolsista do CNPq.
}

RESUMO - Objetivou-se avaliar a influência do tempo de incubação in situ e do tamanho de partículas sobre as estimativas das frações indigestíveis da matéria seca (MSi), da fibra em detergente neutro (FDNi) e da fibra em detergente ácido (FDAi) em alimentos e fezes bovinas. Avaliaram-se amostras de fubá de milho, casca de soja, farelo de trigo, farelo de soja, farelo de algodão, silagem de milho, capim-elefante, cana-de-açúcar, feno de capim-braquiária, palha de milho e fezes de bovinos alimentados com dietas com alto ou baixo nível de concentrado. As amostras foram processadas em moinho com peneiras de porosidade 1, 2 ou $3 \mathrm{~mm}$ e acondicionadas (20 mg MS/cm² de superfície) em sacos de tecido não-tecido $\left(100 \mathrm{~g} / \mathrm{m}^{2}\right)$ de dimensão $4 \times 5 \mathrm{~cm}$. Os materiais foram divididos em três grupos, de modo que as amostras de cada grupo foram incubadas no rúmen de três novilhas mestiças (Holandês $\times$ Zebu). O procedimento de incubação foi repetido três vezes e, a cada período, procedeu-se à incubação dos grupos em animais distintos. Foram utilizados os tempos: 0, 12, 24, 48, 72, 96, 120, 144, 168, 192, 216, 240 e 312 horas. Os teores de MSi, FDNi e FDAi foram avaliados seqüencialmente para interpretação dos perfis de degradação por modelo logístico não-linear. Não houve efeito do tamanho de partículas sobre as estimativas de FDNi e FDAi. Verificaram-se efeitos dos tamanhos de partículas sobre a velocidade de degradação da MS da silagem de milho e do fubá de milho, da FDN da cana-de-açúcar, da silagem de milho e da palha de milho e sobre a velocidade de degradação da FDA da cana-de-açúcar. Para esses alimentos, o tamanho de partícula associou-se positivamente ao tempo necessário para estimar a fração indigestível. Tempos de incubação de 240 horas para MS e FDN e de 264 horas para FDA são recomendados para obtenção de estimativas exatas das frações indigestíveis. O uso de partículas de 2 mm é recomendado por proporcionar maior precisão das estimativas.

Palavras-chave: fibra em detergente ácido indigestível, fibra em detergente neutro indigestível, matéria seca indigestível

\section{Influence of incubation time and particles size on indigestible compounds contents in cattle feeds and feces obtained by in situ procedures}

\footnotetext{
ABSTRACT - The aim of this work was to evaluate the effects of in situ incubation time and particles size on the estimates of indigestible fractions of dry matter (iDM), neutral detergent fiber (iNDF), and acid detergent fiber (iADF) in cattle feeds and feces. Samples of corn grain, wheat bran, corn silage, elephant grass, sugarcane, signal grass hay, corn straw, and feces obtained from cattle fed high and low concentrate diets were used. The samples were ground through $1 \mathrm{~mm}, 2 \mathrm{~mm}$, and $3 \mathrm{~mm}$ screen sieve and put in $4 \times 5 \mathrm{~cm}$ non-woven textile bags (20 mg DM/ $\mathrm{cm}^{2}$ of surface). The samples were divided in three groups, being each group incubated in the rumen of a crossbred heifer. The incubation procedure was conducted three times with the change of groups among animals. The following incubation times were used: 0, 12, 24, 48, 72, 96, 120, 144, 168, 192, 216, 240, and 312 hours. The contents of iDM, iNDF, and iADF were evaluated sequentially in each bag. The degradation profiles were interpreted by a non-linear logistic model. The particles size did not influence the estimates of iNDF and iADF. However, the particles size altered the rumen degradation dynamic rates of DM for corn silage and corn grain; of NDF for sugarcane, corn silage, and corn straw; and ADF for sugarcane. For those samples, the particle size has been positively associated with the incubation time necessary to estimate the indigestible fraction. Incubation times of 240 hours for DM and NDF, and 264 hours for ADF were suggested for obtaining more accurate estimates of indigestible fractions. The use of 2 mm particle size can increase the precision of estimates.
}

Key Words: indigestible acid detergent fiber, indigestible dry matter, indigestible neutral detergent fiber 


\section{Introdução}

A digestibilidade constitui um dos principais parâmetros para avaliação do valor nutritivo de alimentos consumidos por bovinos. Entretanto, sua quantificação pelo método tradicional de coleta total de fezes torna o trabalho oneroso e laborioso, o que torna necessária a utilização de métodos indiretos, como o dos indicadores (internos ou externos), como alternativa à coleta total de fezes, em vitude de sua simplicidade na condução experimental.

Entre os indicadores internos utilizados em ensaios com ruminantes, destacam-se alguns componentes da fração fibrosa dos alimentos, como a fibra em detergente neutro indigestível (FDNi) e a fibra em detergente ácido indigestível (FDAi) (Lippke et al., 1986; Resende et al., 1996; Detmann et al., 2001), e a fração física matéria seca indigestível (MSi) (Huhtanen et al., 1994; Detmann et al., 2001). As concentrações desses indicadores internos em amostras de alimentos e fezes podem ser estimadas por procedimentos in situ (Detmann et al., 2001; Freitas et al., 2002; Ítavo et al., 2002) ou in vitro (Lippke et al., 1986; Berchielli et al., 2000; Freitas et al., 2002). Entretanto, nas incubações in vitro, as partículas fibrosas podem permanecer aderidas à parede e à tampa do tubo e não ter contato com o inóculo ruminal, o que acarreta aumento do resíduo pós-incubação e superestima a quantidade do indicador nas amostras (Freitas et al., 2002).

Esta informação corrobora relatos de Huhtanen et al. (1994) de que a digestibilidade da matéria seca é mais acuradamente predita por meio de resíduos indigestíveis da fibra obtidos por procedimentos in situ em comparação às estimativas obtidas por procedimentos in vitro.

Desta forma, a estimação da concentração de indicadores internos em alimentos e fezes por procedimentos in situ parece ser mais exata que em procedimentos in vitro. Apesar disso, ainda existem divergências quanto à forma de implementação e condução desse método.

O tempo de incubação ruminal é uma das variáveis de maior influência sobre a representatividade dos resíduos indigestíveis em procedimentos de incubação in situ. Não existe na literatura consenso sobre o tempo de incubação ruminal que permita representar melhor a fração indigestível das amostras; observam-se períodos variáveis, como: 96 (Ruiz et al., 2001), 144 (Freitas et al., 2002), 192 (Zeoula et al., 2002 ), 240 (Clipes et al., 2006) e 288 horas (Huhtanen et al., 1994).

A quantificação dos compostos indigestíveis via protocolos in situ também é afetada pela estrutura das partículas dos materiais incubados (Huhtanen et al., 1994;
Detmann et al., 2007a). Segundo Nocek (1988), é difícil estabelecer o tamanho de partículas mais apropriado para estudos in situ, em razão da escassez de informações sobre a associação entre digestão in vivo, in situ e tamanho de partículas. Assim, é necessário identificar tamanhos de partículas para faixa ampla de alimentos.

Diante desses relatos, justifica-se a realização de estudos visando à padronização nos protocolos para estimação dos teores de compostos indigestíveis em procedimentos in situ. Nesta pesquisa, objetivou-se avaliar a influência do tempo de incubação e do tamanho de partículas sobre as estimativas dos compostos indigestíveis MSi, FDNi e FDAi em alimentos e fezes de bovinos.

\section{Material e Métodos}

O experimento foi conduzido nos Laboratórios de Animais e de Nutrição Animal do Departamento de Zootecnia da Universidade Federal de Viçosa, em Viçosa, MG. Foram utilizadas amostras de concentrados protéicos e energéticos, de forragens e de fezes de bovinos (Tabela 1), todas coletadas em Viçosa, MG.

As amostras de forragens úmidas e fezes foram secas em estufa com ventilação forçada $\left(60^{\circ} \mathrm{C}\right.$ por 72 horas) e, juntamente com as demais, foram processadas em moinho de facas com peneiras de porosidade de 1, 2 ou $3 \mathrm{~mm}$. Posteriormente, todas as amostras foram quantificadas quanto aos teores de MS, proteína bruta (PB), fibra em detergente ácido (FDA) e lignina $\left(\mathrm{H}_{2} \mathrm{SO}_{4} 72 \% \mathrm{p} / \mathrm{p}\right)$, segundo métodos descritos por Silva \& Queiroz (2002). As avaliações quanto às concentrações de FDN seguiram os protocolos sugeridos por Mertens (2002), omitindo-se, contudo, a correção relativa às cinzas insolúveis em detergente neutro (Tabela 2).

Tabela 1 - Alimentos e fezes utilizados nos processos analíticos

\begin{tabular}{|c|c|}
\hline Concentrado energético & $\begin{array}{l}\text { Fubá de milho } \\
\text { Casca de soja } \\
\text { Farelo de trigo }\end{array}$ \\
\hline Concentrado protéico & $\begin{array}{c}\text { Farelo de soja } \\
\text { Farelo de algodão }\end{array}$ \\
\hline Forragem & $\begin{array}{c}\text { Silagem de milho } \\
\text { Capim-elefante } \\
\text { Cana-de-açúcar } \\
\text { Feno de capim-braquiária } \\
\text { Palha de milho }\end{array}$ \\
\hline Fezes & $\begin{array}{l}\text { Fezes baixo concentrado }(\mathrm{AC})^{1} \\
\text { Fezes alto concentrado }(\mathrm{BC})^{2}\end{array}$ \\
\hline
\end{tabular}


Tabela 2 - Composição química dos alimentos e das fezes utilizados nas incubações in situ

\begin{tabular}{lrrrrr}
\hline & \multicolumn{5}{c}{ Componente } \\
\cline { 2 - 6 } Material & MS $^{1}$ & PB $^{2}$ & FDN $^{2}$ & FDA $^{2}$ & Lignina $^{2}$ \\
\hline Fubá de milho & 87,29 & 9,33 & 20,91 & 2,85 & 0,89 \\
Casca de soja & 88,32 & 10,32 & 85,11 & 65,17 & 4,22 \\
Farelo de trigo & 87,39 & 16,64 & 38,31 & 10,17 & 4,87 \\
Farelo de soja & 88,02 & 47,59 & 17,60 & 10,29 & 2,54 \\
Farelo de algodão & 89,25 & 50,34 & 23,76 & 10,16 & 9,30 \\
Silagem de milho & 35,57 & 6,42 & 51,07 & 26,36 & 6,34 \\
Capim-elefante & 28,89 & 4,07 & 73,13 & 43,90 & 7,40 \\
Cana-de-açúcar & 21,08 & 3,50 & 50,70 & 27,43 & 9,50 \\
Feno de capim- & 87,32 & 6,80 & 77,31 & 33,59 & 7,85 \\
braquiária & & & & & \\
Palha de milho & 89,06 & 2,27 & 89,84 & 44,46 & 8,80 \\
Fezes BC & 12,47 & 7,03 & 65,68 & 33,89 & 25,00 \\
Fezes AC & 16,05 & 12,52 & 51,94 & 26,09 & 20,60 \\
\hline
\end{tabular}

$1 \%$ da matéria natural.

$2 \%$ MS.

Para avaliação dos teores de componentes indigestíveis, os alimentos e as fezes foram acondicionados em sacos de tecido não-tecido (TNT $-100 \mathrm{~g} / \mathrm{m}^{2}$ ) com dimensões de $4 \times$ $5 \mathrm{~cm}$. As amostras foram acondicionadas, em todos os sacos, na proporção de $20 \mathrm{mg}$ de $\mathrm{MS} / \mathrm{cm}^{2}$ de superfície (Nocek, 1988).

As amostras foram divididas em três grupos (grupo 1: fubá de milho, casca de soja, farelo de trigo e farelo de soja; grupo 2: farelo de algodão, silagem de milho, capim-elefante e cana-de-açúcar; e grupo 3: feno de braquiária, palha de milho e fezes). Cada grupo de amostras foi incubado no rúmen de três novilhas mestiças (Holandês $\times$ Zebu) alimentadas com silagem de capim-elefante e concentrado na proporção 90:10, com base na MS. O procedimento de incubação foi repetido três vezes, de modo que, a cada período, procedeu-se à incubação dos grupos de amostras em animais distintos. Assim, a coleta de dados no campo foi realizada em delineamento quadrado latino $3 \times 3$. Ao final dos procedimentos de incubação, obtiveram-se três amostras para cada material, em cada tamanho de partícula e em cada tempo de incubação.

Foram utilizados os seguintes tempos de incubação: 0, 12, 24, 48, 72, 96, 120, 144, 168, 192, 216, 240 e 312 horas. Os sacos foram dispostos no rúmen em ordem reversa quanto ao tempo de incubação, de modo que sua retirada do rúmen ocorresse simultaneamente. Após a retirada do rúmen, os sacos foram lavados com água corrente até total clareamento e imediatamente transferidos para estufa de ventilação forçada $\left(60^{\circ} \mathrm{C}\right)$, onde foram mantidos por 72 horas. Seqüencialmente, foram secos em estufa não-ventilada $\left(105^{\circ} \mathrm{C}\right.$ por 45 minutos), acondicionados em dessecador (20 sacos/dessecador) e pesados (Detmann et al., 2001) para obtenção da MS não-digerida.
Posteriormente, os sacos foram tratados com detergente neutro (Mertens, 2002) por 1 hora, em equipamento analisador de fibra Ankon ${ }^{\circledR}$, lavados com água quente e acetona, secos e pesados, conforme procedimento anterior, para quantificação da FDN não-digerida. O procedimento descrito para quantificação dos teores de FDN foi novamente realizado, substituindo-se, contudo, o detergente neutro por detergente ácido (Silva \& Queiroz, 2002) a fim de estimar a massa de FDA não-digerida.

Previamente ao processo de incubação, os sacos foram lavados em detergente neutro (Mertens, 2002) e secos de forma similar ao procedimento anterior para obtenção das taras.

Os perfis dos resíduos não-degradados foram interpretados, inicialmente, de forma independente para cada alimento, em cada tamanho de partícula, segundo o modelo (Van Milgen et al., 1991):

$R_{t}=B \cdot(1+k \cdot t) \cdot \exp (-k \cdot t)+I$

em que: $\mathrm{R}_{\mathrm{t}}=$ resíduo não-digerido de MS, FDN ou FDA (\%); $\mathrm{B}=$ fração insolúvel potencialmente degradável da MS, FDN ou FDA (\%); I = fração indegradável (\%), a qual representa os teores de MSi, FDNi ou FDAi; $\mathrm{k}$ = taxa relativa à dinâmica de degradação ruminal da fração insolúvel potencialmente degradável $\left(\mathrm{h}^{-1}\right)$; e $\mathrm{t}=$ tempo de permanência no rúmen (h).

Todos os ajustamentos não-lineares foram realizados conforme protocolos do algoritmo de Gauss-Newton (Souza, 1998).

Para cada indicador obtido em cada alimento, procedeu-se à comparação entre os modelos ajustados para verificar os efeitos do tamanho de partícula sobre as estimativas das frações indigestíveis (MSi, FDNi ou FDAi). Os procedimentos estatísticos foram realizados por meio do teste de identidade de modelos de regressão não-linear, descrito por Regazzi (2003), segundo as hipóteses:

$H_{0}: I_{1 m m}=I_{2 m m}=I_{3 m m} \times H_{a}: n \tilde{a} o H_{0}$

No caso de não-rejeição da hipótese de nulidade descrita em (2), concluiu-se pela ausência de efeito do tamanho de partículas sobre as estimativas de MSi, FDNi ou FDAi. Em caso contrário, conclui-se pela presença de efeito do tamanho de partículas sobre os resíduos indigestíveis.

O efeito de diferentes tamanhos de partículas sobre o tempo necessário para a estimação da fração indigestível foi avaliado por meio do teste de identidade de modelos de regressão não-linear (Regazzi, 2003), segundo as hipóteses:

$H_{0}: k_{1 m m}=k_{2 m m}=k_{3 m m} \times H_{a}: n a ̃ o H_{0}$

Considerando o parâmetro k indicador da velocidade de degradação ruminal (Van Milgen et al., 1991), a influência 
do tamanho de partículas sobre as estimativas deste parâmetro indica, indiretamente, diferenças no tempo necessário para obtenção de estimativas da fração indigestível. Assim, no caso de não-rejeição da hipótese de nulidade descrita em (3), concluiu-se que não há influência do tamanho das partículas incubadas sobre o tempo necessário para se estimar a fração indigestível.

A quantificação dos tempos necessários para a estimação dos resíduos indigestíveis (tempo crítico $-\mathrm{t}_{\mathrm{c}}$ ) foi realizada com base nas propriedades dos intervalos de confiança assintóticos para o parâmetro I (Equação 1). Esse procedimento foi conduzido de forma dependente do diagnóstico dado pelo teste de identidade de modelos descrito anteriormente. No caso de não-rejeição da hipótese de nulidade descrita em (3), um único modelo foi utilizado para todos os tamanhos de partículas. No caso de não-aceitação desta hipótese, modelos distintos para cada tamanho de partícula foram empregados.

As estimativas de tempos críticos $\left(\mathrm{t}_{\mathrm{c}}\right)$ foram obtidas por procedimentos iterativos e consideradas equivalentes ao tempo em que a estimativa do resíduo não-degradado se tornou numericamente idêntica ao limite superior do intervalo de confiança assintótico $(1-\alpha=0,95)$ para o parâmetro I (Figura 1).

Todos os procedimentos estatísticos foram realizados utilizando-se o programa Statistical Analisys System (SAS, 1989). Antecipa-se que o número elevado de perdas de sacos para os alimentos casca de soja, farelo de soja e farelo de algodão comprometeu a confiabilidade de alguns perfis de degradação, que foram omitidos dos resultados e discussão.

\section{Resultados e Discussão}

Em todas as amostras avaliadas, não houve efeito do tamanho de partículas $(\mathrm{P}>0,10)$ sobre a dimensão da fração indigestível da FDN e FDA. A fração MS apresentou comportamento similar, exceto na cana-de-açúcar $(\mathrm{P}<0,10)$.

A dimensão da fração indigestível constitui característica única e exclusiva do substrato (Ørskov, 2000) e não é influenciada pelas condições do meio de fermentação ou por particularidades do material experimental. Diferenças quanto à fração indigestível entre protocolos de avaliação in situ têm sido atribuídas à perda de partículas (Casali et al., 2007).

Neste contexto, o comportamento observado para a FDNi, FDAi e MSi (à exceção da cana-de-açúcar) evindenciou ausência de perda de partículas $(\mathrm{P}>0,10)$ para os tamanhos de partículas estudados. No entanto, o comportamento observado para a MSi com a cana-de-açúcar indica aparentemente perdas de partículas $(\mathrm{P}<0,10)$. A estimativa da fração indigestível foi superior em $3 \mathrm{~mm}(32,07 \%)$ em comparação a 2 mm (28,63\%) e 1 mm (28,51\%). Contudo, caso representasse perda real de partículas, as estimativas de FDNi e FDAi também deveriam ser afetadas, o que não foi verificado $(\mathrm{P}>0,10)$. Ressalta-se que a fração física MSi é constituída de componentes essencialmente insolúveis, de forma similar às frações químicas FDNi e FDAi.

Embora a utilização da MSi como indicador possa produzir resultados exatos, a presença de contaminantes pode comprometer os resultados obtidos (Huhtanen et al., 1994), uma vez que não se utilizam detergentes para se obter o teor de MSi, o que impede a retirada de resíduos

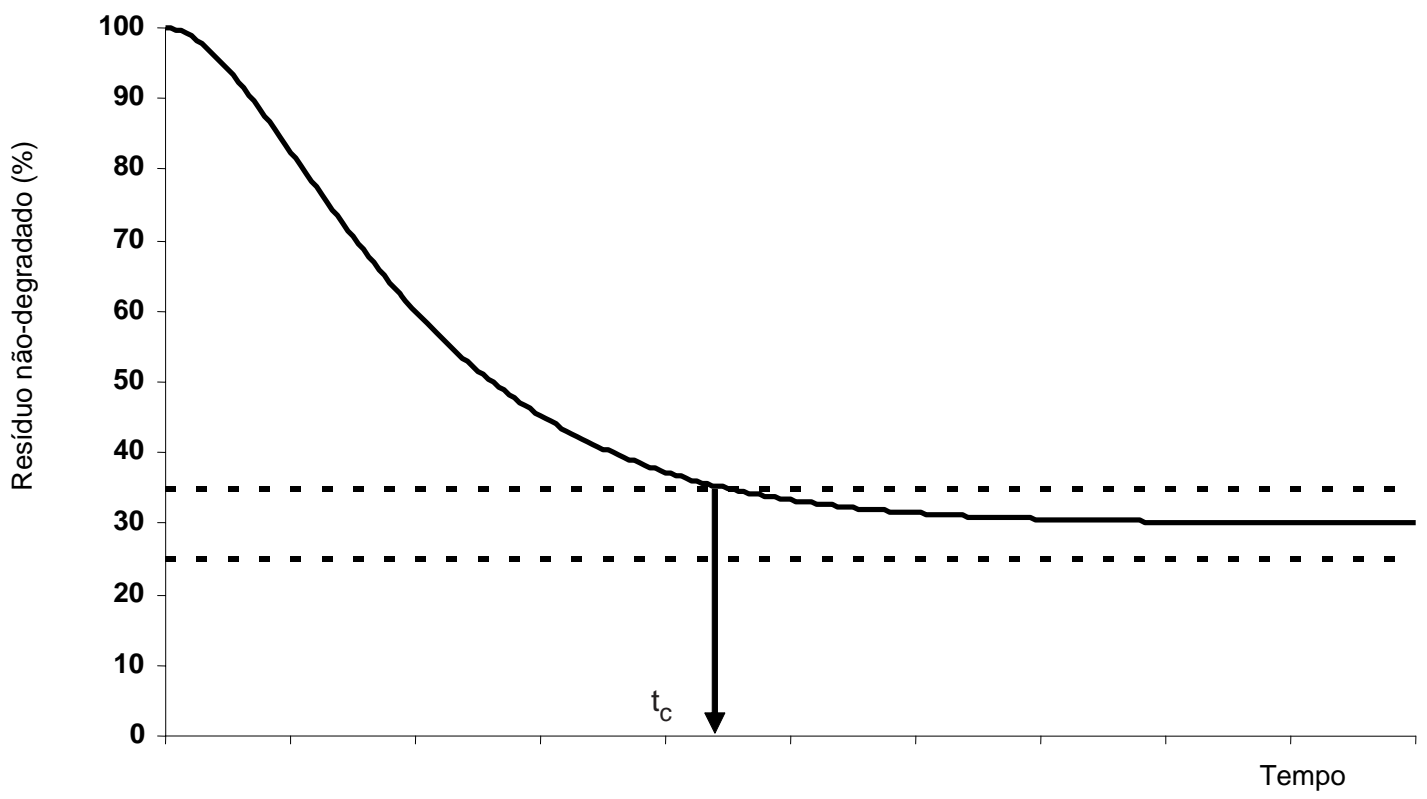

Figura 1 - Exemplo de perfil de degradação ruminal em função do tempo. As linhas tracejadas indicam os limites do intervalo de confiança assintótico para a fração indigestível; $\mathrm{t}_{\mathrm{c}}=$ tempo crítico 
microbianos por ação aniônica (Van Soest, 1994; Clipes et al., 2006). A presença de resíduos aderidos aos tecidos usados para incubação tem sido verificada em condições tropicais (Casali et al., 2007).

A cana-de-açúcar poderia mostrar-se mais sensível à presença de contaminantes microbianos por ser constituída de fibra de baixa qualidade, cuja degradação no rúmen requer elevado tempo de retenção. Por outro lado, o menor grau de moagem (3 mm) reduz a superfície específica para degradação microbiana (Nocek, 1997). Assim, a maior estimativa de MSi para a cana-de-açúcar moída a 3 mm deve-se, possivelmente, à maior contaminação microbiana.

Na análise dos níveis descritivos de probabilidade para o erro tipo I associados à hipótese de nulidade para ausência de efeitos dos diferentes tamanhos de partículas em relação à velocidade de degradação ruminal (Tabela 3), observou-se, para a MSi, não-rejeição da hipótese de nulidade para todos os materiais incubados $(\mathrm{P}>0,10)$, com exceção da silagem de milho e do fubá de milho $(\mathrm{P}<0,10)$. Comportamento similar foi verificado para a FDNi; houve efeitos significativos $(\mathrm{P}<0,10)$ somente para a cana-de-açúcar, a silagem de milho e a palha de milho. Para a FDAi, efeitos relativos ao tamanho de partículas foram verificados somente para a cana-deaçúcar $(\mathrm{P}<0,10)$.

De modo geral, a ocorrência de efeitos significativos do tamanho de partículas foi mais observada em alimentos fibrosos em comparação aos alimentos concentrados e às fezes (Tabela 3). Apesar de compor as amostras com maior lignificação (Tabela 2), as fezes constituem material reincidente ao ambiente ruminal, o que implica características distintas dos demais alimentos fibrosos, como a cana-deaçúcar, e justifica o comportamento distinto em relação a esses materiais.

Tabela 3 - Níveis descritivos de probabilidade para o erro tipo I associados à hipótese de nulidade para ausência de diferenças entre tamanhos de partículas quanto à velocidade de degradação ruminal

\begin{tabular}{lccc}
\hline & \multicolumn{3}{c}{ Componente } \\
\cline { 2 - 4 } Material & MS & FDN & FDA \\
\hline Capim-elefante & 0,2283 & 0,3681 & 0,6959 \\
Feno de braquiária & 0,9489 & 0,4311 & 0,4177 \\
Cana-de-açúcar & 0,2863 & 0,0334 & 0,0208 \\
Silagem de milho & 0,0117 & 0,0956 & 0,1233 \\
Palha de milho & 0,2779 & 0,0371 & 0,2825 \\
Fezes (AC) & 0,9371 & 0,9217 & 0,2449 \\
Fezes (BC) & 0,8829 & 0,9130 & 0,2536 \\
Casca de soja & 0,4558 & 0,6663 & - \\
Farelo de trigo & 0,7486 & 0,2642 & 0,7171 \\
Farelo de soja & 0,6244 & - & - \\
Fubá de milho & 0,0179 & 0,1364 & 0,6437 \\
Farelo de algodão & 0,3251 & - & - \\
\hline
\end{tabular}

No caso dos alimentos em que ocorreu efeito significativo do tamanho de partículas sobre a velocidade de degradação (Tabela 3), houve relação diretamente proporcional entre o tamanho da partícula e o tempo crítico $\left(\mathrm{t}_{\mathrm{c}}\right)$ para obtenção da fração indigestível da MS, FDN e FDA (Tabelas 4, 5 e 6); ou seja, quanto maior o tamanho da partícula, maior o tempo necessário para se estimar acuradamente o teor de compostos indigestíveis.

$\mathrm{O}$ maior $\mathrm{t}_{\mathrm{c}}$ com aumento do tamanho das partículas parece estar associado à redução da superfície específica para a ação microbiana (Nocek, 1997). Ressalta-se, no entanto, que a redução do tamanho das partículas dos alimentos acondicionados nos sacos é limitada em comparação ao alimento livremente ingerido pelo animal, uma vez que não ocorrem atividades mastigatórias e que as ações mecânicas de atrito entre partículas são restritas tornando a ação microbiana sobre a redução das partículas proporcionalmente mais relevante.

O tempo de incubação ruminal consiste em uma das variáveis de maior influência sobre a representatividade dos resíduos indigeridos em procedimentos de incubação in situ. Por definição, a fração indigestível constitui conceito assintótico, ou seja, representa a fração incapaz de ser aproveitada pelos sistemas enzimáticos microbiano e animal quando não há limitação no tempo de exposição a esses

Tabela 4 - Estimativas para a taxa relativa à dinâmica de degradação ruminal $\left(\mathrm{k}-\mathrm{h}^{-1}\right)$ e fração indigestível da matéria seca (MSi - \% da MS), limite superior do intervalo de confiança assintótico com $95 \%$ de probabilidade para a fração indigestível (LS - \% da MS) e tempo crítico $\left(\mathrm{t}_{\mathrm{c}}-\mathrm{h}\right)$ para o alcance da fração MSi com diferentes tamanhos de partículas

\begin{tabular}{lccccc}
\hline & & \multicolumn{4}{c}{ Parâmetro } \\
\cline { 3 - 6 } Material & Partícula & $\mathrm{k}$ & $\mathrm{MSi}$ & $\mathrm{LS}$ & $\mathrm{t}_{\mathrm{c}}$ \\
\hline Capim-elefante & - & 0,0284 & 37,66 & 39,68 & 170,8 \\
Feno de braquiária & - & 0,0389 & 26,52 & 28,12 & 139,1 \\
Cana-de-açúcar & - & 0,0349 & 29,70 & 30,97 & 137,5 \\
Silagem de milho & $1 \mathrm{~mm}$ & 0,0287 & 20,27 & 22,94 & 156,8 \\
Silagem de milho & $2 \mathrm{~mm}$ & 0,0244 & 20,58 & 23,12 & 186,7 \\
Silagem de milho & $3 \mathrm{~mm}$ & 0,0208 & 19,42 & 22,74 & 207,8 \\
Palha de milho & - & 0,0228 & 19,48 & 22,36 & 217,2 \\
Fezes (AC) & - & 0,0299 & 28,00 & 30,15 & 154,9 \\
Fezes (BC) & - & 0,0259 & 43,74 & 46,29 & 167,8 \\
Casca de soja & - & 0,0350 & 4,54 & 6,39 & 162,1 \\
Farelo de trigo & - & 0,0591 & 15,29 & 16,48 & 87,8 \\
Farelo de soja & - & 0,0538 & 4,03 & 6,63 & 88,4 \\
Fubá de milho & $1 \mathrm{~mm}$ & 0,0627 & 3,45 & 5,21 & 88,2 \\
Fubá de milho & $2 \mathrm{~mm}$ & 0,0513 & 3,03 & 5,21 & 104,2 \\
Fubá de milho & $3 \mathrm{~mm}$ & 0,0503 & 3,13 & 5,38 & 106,6 \\
Farelo de algodão & - & 0,0357 & 16,23 & 18,24 & 138,3 \\
Média & - & - & - & - & 144,6 \\
Máximo & - & - & - & - & 217,2 \\
Mínimo & - & - & - & - & 87,8 \\
CV (\%) & - & - & - & - & 28,6 \\
\hline
\end{tabular}


Tabela 5 - Estimativas para a taxa relativa à dinâmica de degradação ruminal $\left(k-h^{-1}\right)$ e fração indigestível da fibra em detergente neutro (FDNi - \% da FDN), limite superior do intervalo de confiança assintótico com 95\% de probabilidade para a fração indigestível (LS - \% da FDN) e tempo crítico $\left(t_{c}-h\right)$ para o alcance da fração FDNi com diferentes tamanhos de partícula

\begin{tabular}{lccccc}
\hline & & \multicolumn{4}{c}{ Parâmetro } \\
\cline { 3 - 6 } Material & Partícula & $\mathrm{k}$ & FDNi & $\mathrm{LS}$ & $\mathrm{t}_{\mathrm{c}}$ \\
\hline Capim-elefante & - & 0,0277 & 44,46 & 46,94 & 176,1 \\
Feno de braquiária & - & 0,0401 & 28,92 & 30,76 & 135,5 \\
Cana-de-açúcar & $1 \mathrm{~mm}$ & 0,0366 & 49,87 & 53,70 & 115,4 \\
Cana-de-açúcar & $2 \mathrm{~mm}$ & 0,0324 & 50,71 & 53,32 & 144,5 \\
Cana-de-açúacar & $3 \mathrm{~mm}$ & 0,0248 & 54,70 & 58,04 & 176,6 \\
Silagem de milho & $1 \mathrm{~mm}$ & 0,0236 & 29,59 & 32,98 & 204,1 \\
Silagem de milho & $2 \mathrm{~mm}$ & 0,0213 & 30,62 & 36,52 & 196,5 \\
Silagem de milho & $3 \mathrm{~mm}$ & 0,0188 & 29,39 & 32,56 & 268,6 \\
Palha de milho & $1 \mathrm{~mm}$ & 0,0294 & 18,67 & 24,21 & 142,5 \\
Palha de milho & $2 \mathrm{~mm}$ & 0,0225 & 19,87 & 25,61 & 186,9 \\
Palha de milho & $3 \mathrm{~mm}$ & 0,0203 & 17,54 & 24,85 & 193,6 \\
Fezes (AC) & - & 0,0230 & 40,66 & 44,00 & 195,1 \\
Fezes (BC) & - & 0,0231 & 52,56 & 55,76 & 186,9 \\
Casca de soja & - & 0,0315 & 3,24 & 5,13 & 177,3 \\
Farelo de trigo & - & 0,0305 & 29,45 & 31,72 & 166,0 \\
Farelo de soja & - & - & - & - & - \\
Fubá de milho & - & 0,0353 & 8,2 & 10,3 & 154,5 \\
Farelo de algodão & - & - & - & - & - \\
Média & - & - & - & - & 176,3 \\
Máximo & - & - & - & - & 268,6 \\
Mínimo & - & - & - & - & 115,4 \\
CV(\%) & - & - & - & - & 20,0 \\
\hline
\end{tabular}

Tabela 6 - Estimativas para a taxa relativa à dinâmica de degradação ruminal $\left(\mathrm{k}-\mathrm{h}^{-1}\right)$ e fração indigestível da fibra em detergente ácido (FDAi - \% da FDA), limite superior do intervalo de confiança assintótico com 95\% de probabilidade para a fração indigestível (LS - \% da FDA) e tempo crítico $\left(t_{c}\right)$ para obtenção da fração FDAi com diferentes tamanhos de partícula

\begin{tabular}{lccccc}
\hline & & \multicolumn{4}{c}{ Parâmetro } \\
\cline { 3 - 6 } Material & Partícula & $\mathrm{k}$ & FDAi & $\mathrm{LS}$ & $\mathrm{t}_{\mathrm{c}}$ \\
\hline Capim-elefante & - & 0,0239 & 46,22 & 49,08 & 196,1 \\
Feno de braquiária & - & 0,0353 & 32,82 & 35,05 & 148,1 \\
Cana-de-açúcar & $1 \mathrm{~mm}$ & 0,0306 & 55,80 & 59,15 & 141,8 \\
Cana-de-açúcar & $2 \mathrm{~mm}$ & 0,0240 & 55,26 & 59,16 & 174,5 \\
Cana-de-açúcar & $3 \mathrm{~mm}$ & 0,0173 & 61,40 & 69,86 & 182,5 \\
Silagem de milho & - & 0,0187 & 30,60 & 34,64 & 248,8 \\
Palha de milho & - & 0,0192 & 14,33 & 18,76 & 240,5 \\
Fezes (AC) & - & 0,0218 & 44,34 & 47,70 & 207,0 \\
Fezes (BC) & - & 0,0194 & 56,12 & 60,59 & 203,0 \\
Casca de soja & - & - & - & - & - \\
Farelo de trigo & - & 0,0246 & 58,70 & 61,50 & 188,5 \\
Farelo de soja & - & - & - & - & - \\
Fubá de milho & - & 0,0261 & 27,27 & 31,19 & 174,6 \\
Farelo de algodão & - & - & - & - & - \\
Média & - & - & - & - & 191,4 \\
Máximo & - & - & - & - & 248,8 \\
Mínimo & - & - & - & - & 141,8 \\
CV(\%) & - & - & - & - & 17,4 \\
\hline
\end{tabular}

sistemas (Mertens, 1993). Assim, o valor real da fração indigestível somente poderá ser verdadeiramente mensurado em procedimentos conduzidos em escala de tempo infinita. Contudo, em termos práticos, os procedimentos in situ são baseados em escalas finitas de tempo, assumindo-se intervalo temporal relativamente elevado de forma que as estimativas obtidas (resíduo indigerido) se aproximem do conceito assintótico (resíduo indigestível).

Segundo Mertens (1993), estimativas acuradas da fração indigestível seriam obtidas em tempos de incubação iguais a 4,6 vezes a recíproca da taxa representativa da dinâmica de degradação ruminal. Neste contexto, segundo as taxas médias observadas neste estudo $\left(0,0377 \mathrm{~h}^{-1}\right.$ para MS; $0,0276 \mathrm{~h}^{-1}$ para FDN; e $0,0237 \mathrm{~h}^{-1}$ para FDA), seriam necessários tempos de 122,1, 166,9 e 193,9 horas para obtenção das estimativas de MSi, FDNi e FDAi, respectivamente.

Contrastando esses valores aos $t_{c}$ médios observados para cada indicador (Tabelas 4, 5 e 6), verifica-se que esta relação, quando baseada nos valores médios da taxa relacionada à dinâmica de degradação ruminal, somente assume valores próximos para a FDAi $(4,54)$, ao passo que subestimaria as relações necessárias para obtenção de estimativas da fração indigestível da MS e da FDN (relações de 5,45 e 4,86, respectivamente). Esta divergência torna a recomendação de Mertens (1993) pouco exata para condições tropicais, o que parece refletir questões de diferenças na dinâmica de degradação ruminal entre alimentos produzidos em condições tropicais e não-tropicais (Detmann et al., 2007b).

De modo geral, os tempos médios obtidos para a obtenção das frações indigestíveis da MS, FDN e FDA (144,6; 176,3; e 191,4 horas, respectivamente) encontram-se em patamares superiores em relação aos tempos comumente empregados para estimação de frações indigestíveis em experimentos de digestibilidade e/ou consumo a pasto (ex.: 96 horas - Ruiz et al., 2001; 144 horas - Detmann et al., 2001; Freitas et al., 2002; Ítavo et al., 2002; Detmann et al., 2005). Este comportamento pode conferir menor exatidão às estimativas de coeficientes de digestibilidade ou de consumo voluntário de pasto.

Berchielli et al. (2005) abordaram essa divergência ao avaliarem os indicadores FDNi e FDAi. Esses autores relataram que os teores desses indicadores foram muito variáveis nos alimentos avaliados, indicando, provavelmente, que incubações em tempos inferiores a 144 podem não resultar em estimativas adequadas da fração total indigestível. Huhtanen et al. (1994) também sugeriram que períodos de incubação inferiores a 288 horas podem não permitir boa aproximação à fração potencialmente degradável (e, conseqüentemente, indegradável). 
Os valores médios de tempo crítico observados (Tabelas 4, 5 e 6) foram mais próximos ao proporto por Clipes et al. (2006), que, ao estudarem a fração indigestível dos compostos nitrogenados associados à parede celular em gramíneas tropicais, sugeriram tempo de incubação in situ de 240 horas como medida de maior aproximação da fração nãodegradada ao real valor da fração indegradável.

Embora os valores médios indiquem a necessidade do estabelecimento de tempos superiores de incubação aos comumente empregados, há grande variabilidade dos tempos críticos entre indicadores e alimentos, de 87,8 (MSi farelo de trigo) a 268,6 horas (FDNi - silagem de milho $3 \mathrm{~mm}$ ). Esta variabilidade confirma relatos de Detmann et al. (2007a) de que diferentes materiais poderiam demandar protocolos distintos para estimativa da fração indigestível da MS, FDN e FDA.

Para os indicadores MSi e FDNi, não foram observados $\mathrm{t}_{\mathrm{c}}$ superiores a 240 horas (Figura 2), sugerindo que este tempo de incubação seria adequado para a obtenção de estimativas exatas destas frações indigestíveis. A sugestão de protocolos com base nos maiores valores de tempo exigidos propicia a obtenção de estimativas mais exatas da fração indigestível, mesmo em alimentos que demandam baixos $t_{c}$, uma vez que propiciará somente maior aproximação ao real valor assintótico. A adoção de tempo único para todas as amostras obtidas em experimento propicia maior padronização dos protocolos e melhor comparação dos valores obtidos em diferentes experimentos.

Em virtude da ocorrência de valores de $t_{c}$ superiores a 240 horas (silagem de milho, 248,8 horas; palha de milho, 240,5 horas) para a FDAi (Figura 2), sugere-se a padronização do tempo de incubação in situ em mais 24 horas em relação aos demais indicadores, com protocolo de 264 horas.

Por outro lado, como o tamanho de partículas não influencia a dimensão das frações indigestíveis $(\mathrm{P}>0,10)$, a escolha do tamanho para compor os protocolos deve ser feita com base na precisão das estimativas obtidas.

A avaliação dos erros-padrão assintóticos para as estimativas das frações indigestíveis indicou que o uso de partículas com $3 \mathrm{~mm}$ reduz a precisão dos resultados (Figura 3), possivelmente em virtude da menor superfície específica para ação microbiana. O uso de partículas com 1 e $2 \mathrm{~mm}$ possibilita obter estimativas similares em precisão (Figura 3).

Complementando recomendações para protocolos in situ (Hvelpund \& Weisbjerg, 2000; NRC, 2001), sugere-se a padronização da preparação de amostras utilizando-se peneiras com porosidade de $2 \mathrm{~mm}$.

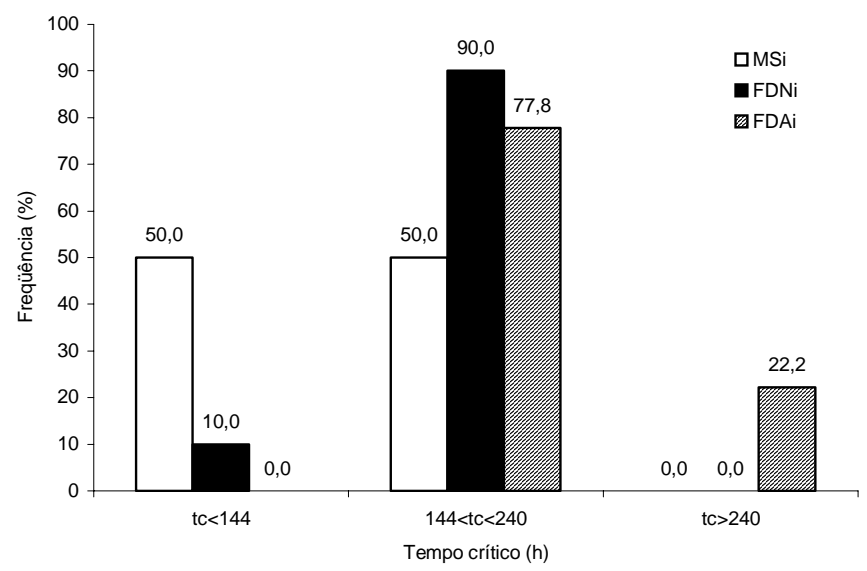

Figura 2 - Freqüência de distribuição dos tempos críticos em função dos indicadores MSi, FDNi e FDAi. Para os alimentos nos quais se verificou efeito do tamanho de partículas, consideraram-se para o cálculo das freqüências apenas as estimativas de tempo crítico obtidas com $2 \mathrm{~mm}$.

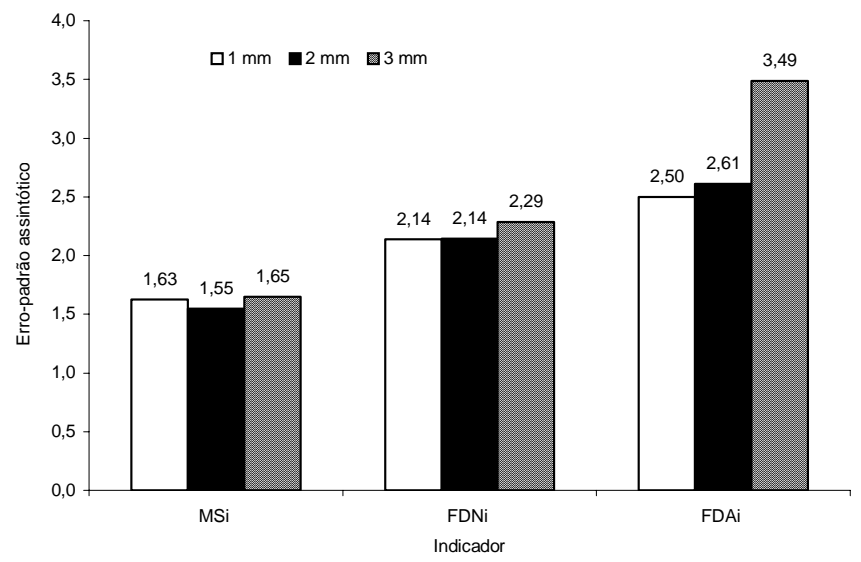

Figura 3 - Comportamento médio dos erros-padrão assintóticos para a fração indigestível obtidos com diferentes tamanhos de partículas.

\section{Conclusões}

Sugere-se a utilização de partículas de 2 mm em protocolos in situ por possiblitar maior precisão das estimativas. Utilizando-se sacos confeccionados com TNT em protocolos de estimação in situ dos teores de MSi e FDNi, devem ser utilizados tempos de incubação de 240 horas para obtenção de estimativas mais exatas das frações indigestíveis. Para avaliação da fração FDAi, sugerem-se tempos de 264 horas. 


\section{Literatura Citada}

BERCHIELLI, T.T.; ANDRADE, P.; FURLAN, C.L. et al. Avaliação de indicadores internos em ensaios de digestibilidade. Revista Brasileira de Zootecnia, v.29, p.830-833, 2000.

BERCHIELLI, T.T.; OLIVEIRA, S.G.; FEITOSA, W. et al. Estimativas da produção fecal e digestibilidade total em bovinos por meio de indicadores. In: REUNIÃO ANUAL DA SOCIEDADE BRASILEIRA DE ZOOTECNIA, 42., 2005, Goiânia. Anais... Goiânia: Sociedade Brasileira de Zootecnia, 2005. (CD-ROM).

CASALI, A.O.; DETMANN, E.; VALADARES FILHO, S.C. et al. Estimação in situ dos teores de fibra em detergente neutro indigestível em alimentos para ruminantes em sacos de diferentes tecidos. Revista Brasileira de Zootecnia, 2007 (em tramitação).

CLIPES, R.C.; DETMANN, E.; COELHO DA SILVA, J.F. et al. Evaluation of acid detergent insoluble protein as an estimator of rumen non-degradable protein in tropical grass forages. Arquivo Brasileiro de Medicina Veterinária e Zootecnia, v.58, p.694-697, 2006.

DETMANN, E.; PAULINO, M.F.; ZERVOUDAKIS, J.T. et al. Cromo e indicadores internos na determinação do consumo de novilhos mestiços, suplementados, a pasto. Revista Brasileira de Zootecnia, v.30, p.1600-1609, 2001.

DETMANN, E.; PAULINO, M.F.; CECON, P.R. et al. Níveis de proteína em suplementos para terminação de bovinos em pastejo durante o período de transição seca/águas: consumo voluntário e trânsito de partículas. Revista Brasileira de Zootecnia, v.34, p.1371-1379, 2005.

DETMANN, E.; SOUZA, A.L.; GARCIA, R. et al. Avaliação do vício de "tempo longo" de indicadores internos em ensaios de digestão com ruminantes. Arquivo Brasileiro de Medicina Veterinária e Zootecnia, v.59, p.182-188, 2007a.

DETMANN, E.; VALADARES FILHO, S.C.; PINA, D.S. et al. Prediction of the energy value of cattle diets based on the chemical composition of the feeds under tropical conditions. Animal Feed Science and Technology, 2007b (in press).

FREITAS, D.; BERCHIELLI, T.T.; SILVEIRA, R.N. et al. Produção fecal e fluxo duodenal de matéria seca e matéria orgânica estimados através de indicadores. Revista Brasileira de Zootecnia, v.31, p.1521-1530, 2002.

HUHTANEN, P.; KAUSTELL, K.; JAAKKOLA, S. The use of internal markers to predict total digestibility and duodenal flow of nutrients in cattle given six different diets. Animal Feed Science and Technology, v.48, p.211-227, 1994.

HVELPLUND, T.; WEISBJERG, M.R. In situ techniques for the estimation of protein degradability and postrumen availability In: GIVENS, D.I.; OWEN, E.; AXFORD, R.F.E. et al. (Eds.) Forage evaluation in ruminant nutrition. London: $\mathrm{CAB}$ International, 2000. p.233-258.

ÍTAVO, L.C.V.; VALADARES FILHO, S.C.; SILVA, F.F. et al Consumo, degradabilidade ruminal e digestibilidade aparente de fenos de gramíneas do gênero Cynodon e rações concentradas utilizando indicadores internos. Revista Brasileira de Zootecnia, v.31, p.1024-1032, 2002.

LIPPKE, H.; ELLIS, W.C.; JACOBS, B.F. Recovery of indigestible fiber from feces of sheep and cattle on forage diets. Journal of Dairy Science, v.69, p.403-412, 1986.

MERTENS, D.R. Rate and extent of digestion. In: FORBES, J.M.; FRANCE, J. (Eds.). Quantitative aspects of ruminant digestion and metabolism. Wallingford: $C A B$ Publishing, 1993. p.13-51.

MERTENS, D.R. Gravimetric determination of amylase-treated neutral detergent fiber in feeds with refluxing in beaker or crucibles: collaborative study. Journal of AOAC International, v.85, p.1217-1240, 2002.

NATIONAL RESEARCH COUNCIL - NRC. Nutrient requirements of dairy cattle. 7.ed. Washington: Academic Press, 2001. 381p.

NOCEK, J.E. In situ and other methods to estimate ruminal protein and energy digestibility: a review. Journal of Dairy Science, v.71, p.2051-2069, 1988.

NOCEK, J.E. In situ and other methods to estimate ruminal protein and energy digestibility: a review. In: TEIXEIRA, J.C. (Ed.) Digestibilidade em ruminantes. Lavras: FAEPE, 1997. p.197-240.

ØRSKOV, E.R. The in situ technique for the estimation of forage degradability in ruminants. In: GIVENS, D.I.; OWEN, E.; AXFORD, R.F.E. et al. (Eds.) Forage evaluation in ruminant nutrition. London: CAB International, 2000. p.175-188.

REGAZZI, A.J. Teste para verificar a igualdade de parâmetros e a identidade de modelos de regressão não linear. Revista Ceres, v.50, p.9-26, 2003.

RESENDE, K.T.; FURLAN, C.L.; COSTA, R.G. et al. Utilização do colágeno cromatado como indicador em estudos de digestão com caprinos. Revista da Sociedade Brasileira de Zootecnia, v.25, p.807-813, 1996

RUIZ, R.; van SOEST, P.J.; van AMBURGH, M.E. et al. Use of chromium mordanted neutral detergent residue as a predictor of fecal output to estimate intake in grazing high production Holstein cows. Animal Feed Science and Technology, v.89, p.155-164, 2001.

STATISTICAL ANALISYS SYSTEM - SAS. SAS/STAT user's guide. 4.ed. Cary: 1989. v.2, 846p.

SILVA, D.J.; QUEIROZ, A.C. Análises de alimentos (métodos químicos e biológicos). 3.ed. Viçosa, MG: Editora UFV, 2002. 235p.

SOUZA, G.S. Introdução aos modelos de regressão linear e não-linear. Brasília: EMBRAPA-SPI, 1998. 505p.

Van MILGEN, J.; MURPHY,L.L.; BERGER, L.L. A compartmental model to analyze ruminal digestion. Journal of Dairy Science, v.74, p.2515-2529, 1991.

Van SOEST, P.J. Nutritional ecology of the ruminant. 2.ed. Ithaca: Cornell University Press, 1994. 476p.

ZEOULA, L.M.; PRADO, I.N.; DIAN, P.H.M. et al. Recuperação fecal de indicadores internos avaliados em ruminantes. Revista Brasileira de Zootecnia, v.31, p.1865-1874, 2002. 